\title{
Rothmund-Thomson syndrome associated with trisomy 8 mosaicism
}

\author{
K L Ying, Jun Oizumi, Cynthia J R Curry
}

\begin{abstract}
This report describes a boy with RothmundThomson syndrome associated with trisomy 8 mosaicism. The patient presented with typical features of Rothmund-Thomson syndrome but some of the features often seen in trisomy $\mathbf{8}$ mosaics were also observed in him. The possibility that the two disorders might share a common pathogenesis is postulated.
\end{abstract}

Rothmund-Thomson syndrome (poikiloderma congenitale syndrome) was first described by Rothmund ${ }^{1}$ in 1868 and later by Thomson ${ }^{2}$ in 1923 and 1936. It is a rare autosomal recessive disorder with major manifestations involving skin, eye, and skeletal systems. Characteristic skin changes are generally evident between 3 and 6 months of age when erythematous plaques develop on the face, gradually extending onto the dorsum of the hands and extensor surfaces of the legs and thighs. ${ }^{4}$ Eventually the skin lesions progress to dermal atrophy, telangiectasia, depigmentation, and hyperpigmentation. About half of the reported cases have ocular lesions, most commonly juvenile zonular cataract, and occasionally corneal dystrophy. ${ }^{5}$ Skeletal involvement includes

Division of Medical Genetics, Children's Hospital of Los Angeles, 4650 Sunset Boulevard, PO Box 54700 Los Angeles, CA 90054, USA.

$\mathrm{K}$ L Ying, J Oizumi

Division of Metabolism, National Children's Medical Research Center, Tokyo, Japan.

J Oizumi

Division of Medical Genetics, Valley Children's Hospital, Fresno, CA 93703, USA.

C J R Curry

Correspondence to Dr Ying.

Received for publication 8 August 1989.

Accepted for publication 29 August 1989. hypoplasia or absence of the radii and thumbs, osteopenia, and cystic or sclerotic changes of the long bones.

Chromosome analysis has been pursued in a number of cases of Rothmund-Thomson syndrome. However, there is no previously reported association between Rothmund-Thomson syndrome and any chromosome abnormality. ${ }^{6}$

Clinical and cytogenetic findings of trisomy 8 mosaicism have been reported in many affected subjects. ${ }^{7}$ Two-thirds of these had low frequency mosaicism for the trisomic cell line. The differences in the proportion of trisomy 8 versus normal cells may account for the wide variation of clinical manifestations. However, deep set eyes, abnormal ears, and skeletal involvement seem to be relatively common features.

This report describes an 8 year old boy who presented with typical features of RothmundThomson syndrome with some additional phenotypic abnormalities and was also found to have trisomy 8 mosaicism.

\section{Case report}

The patient was the product of an uncomplicated, 36 week pregnancy in a healthy, 24 year old, G4,P1,TAB3 Puerto Rican mother and healthy, unrelated young Puerto Rican father. Family history was unremarkable. Vaginal delivery was uncomplicated. Birth weight was $1600 \mathrm{~g}$, height was $47 \mathrm{~cm}$, and head circumference $32.5 \mathrm{~cm}$, all below the 5 th centile.

Physical examination showed a dysmorphic facial appearance with relative macrocephaly, prominent forehead, triangular, flat facies, narrow palpebral fissures, deep set eyes, small, saddle nose, micrognathia, and low set ears with crumpled auricles. The chest was narrow and symmetrical. No heart murmur was audible. Abdominal examination was unremarkable. The testes were borderline small. Both thumbs were extremely hypoplastic and dangling. Camptodactyly of the second and fifth fingers was noted bilaterally. Bilateral simian creases were observed. 
The nails were normal. Radiographs of the hands and arms indicated absence of the first metacarpals bilaterally and hypoplastic radii.

Weight gain in infancy was slow. Characteristic skin lesions developed on the face and extremities when he was approximately 6 months old. The cutaneous findings worsened with exposure to sunlight. Otherwise, he remained well. He began to roll over at 6 months, crawled at 7 months, walked at 1 year, and uttered a few words at 15 months of age. Before the development of skin lesions, he carried a working diagnosis of Fanconi pancytopenia syndrome, although there were no haematological abnormalities. His hands were treated surgically by bilateral pollicisation.

When he was first seen in the Genetics Clinic at 8 years of age, he presented with typical skin lesions, but without any signs of cataracts. Height and weight were both on the 5th centile, and the head circumference was on the 3 rd centile. His facial appearance and hand deformities are shown in the figure. His teeth were also noted to be hypoplastic. IQ was 88 on the Stanford-Binet scale and 83 by the Peabody picture vocabulary test. Other than avoidance of sunlight, no special medical care was recommended.

Radiological findings were typical of those seen in Rothmund-Thomson syndrome, including generalised osteopenia, linear sclerotic deformity of the tibial metaphysis along its medial aspect, radiolucent lesions of both tibiae, fragmentation of the first metacarpals, and a marked delay in bone age. Routine haematological analysis was normal.

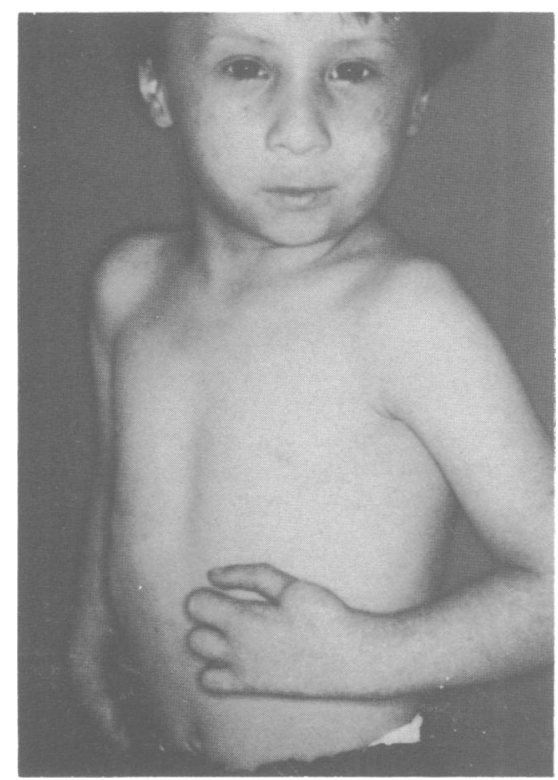

The proband.
CYTOGENETIC STUDIES

Cytogenetic investigation was performed using PHA stimulated lymphocytes harvested after 72 hours' culture for standard GTG analysis and after 48 hours' culture for chromosomal breakage study. Peripheral blood was obtained on two different occasions. In the first study, there was no evidence of chromosome breakage, gaps, or markers. Out of 125 cells examined, 122 cells had a normal number of 46 chromosomes and $\mathrm{G}$ banded karyotypes showed a normal male chromosome constitution. The remaining three cells $(2 \cdot 4 \%)$, however, each had an additional chromosome 8.

Repeat cytogenetic evaluation was performed one year later. Trisomy 8 was again detected in five out of 195 cells $(2 \cdot 5 \%)$ examined. Low frequency trisomy 8 was thus confirmed in lymphocytes from this patient. It is of interest to note that the proportion of trisomic cells was consistent in both samples. Again, no chromosome breakage was observed. Skin biopsies from the hyperpigmented, atrophied areas did not grow in culture on two separate occasions. A third biopsy taken from a healthy region of skin yielded analysable metaphases from cells harvested in the third passage. In addition to a normal $46, \mathrm{XY}$ cell line seen in seven cells, a major abnormal clone, $47, \mathrm{XY}$, + iso( $8 q)$ was identified in 72 cells. There were also isolated abnormal clones and individual cells including the following: 47,XY, +2 (two cells); 47,XY, +iso(2q) (two cells); 47,XY, $-2,+$ iso( $2 p$ ), +iso(2q)(three cells); $46, \mathrm{XY},-7,+$ iso(7q) (one cell); 47,XY, +iso(7p) (one cell); 45,XY, $-7,-15,+\operatorname{der}(7 \mathrm{q} 15 \mathrm{q}), \mathrm{t}(7 ; 15)$ (cen;cen) (one cell); 48,XY, + iso( $8 \mathrm{q})$, +iso(2lq) (one cell). No straightforward trisomy 8 cells were identified.

\section{Discussion}

We have described a patient with low frequency mosaicism for trisomy 8 , and features consistent with the clinical diagnosis of Rothmund-Thomson syndrome. The medical term 'poikiloderma' literally means variable skin. The skin lesion of RothmundThomson syndrome, therefore, is sometimes difficult to distinguish from other skin lesions. In a summary of the findings in this syndrome, Hall et $a l^{8}$ described a case with the absence of both thumbs and hypoplastic radii as seen in our patient. According to the authors, this defect has been observed in $5 \%$ of cases with this syndrome.

It is of interest that another syndrome with poikiloderma, focal dermal hypoplasia, or Goltz syndrome, shows markedly delayed or even absent growth of skin fibroblasts from biopsy of the skin lesions. ${ }^{9}$ The failure of our patient's skin cultures to grow may reflect the same phenomenon. However, it was fortunate that the biopsy fibroblasts from healthy skin did grow. The cytogenetic findings from these cells were informative, confirming an abnormality involving chromosome 8 . The presence of isochromo- 
some (8q) in skin fibroblasts suggests that there were pre-existing trisomy 8 cells in addition to the normal cell line. The additional chromosome 8 gave rise to the iso( $8 \mathrm{q})$ clone, which constituted the majority $(80 \%)$ of the skin fibroblast cell population sampled. A minor abnormal clone was identified to be $47, X Y,+2$, which subsequently gave rise to iso( $2 q)$ and iso(2q)/iso(2p) sub-cell lines. A unique feature of the mechanism involved in the various structural arrangements as identified was that they were all derived via centromere misdivision or breakage.

Schinzel $e t a l^{7}$ summarised 35 cases of trisomy 8 mosaicism and noted a number of clinical features similar to some of those reported in RothmundThomson syndrome and observed in our patient. These include relative macrocranium, prominent forehead, deep set eyes, hypertelorism, broad nasal root, pinna anomaly, micrognathia, joint limitation, camptodactyly, long and slender trunk, and hypogonadism. It seems possible that the overlapping clinical features of the two syndromes, especially skeletal deformities, may share a common aetiology.

The findings of trisomy 8 cells in our case is interesting. Since low frequency mosaicism could very well be missed if insufficient numbers of cells were examined, it would be worthwhile to reinvestigate previously reported cases and see if they also have trisomy 8 or its derivatives, particularly in fibroblast cultures. Rothmund-Thomson syndrome is reported to have an autosomal recessive mode of inheritance, ${ }^{10} 11$ whereas trisomic mosaicism normally arises as a result of a post-zygotic nondisjunction event. Whether or not the latter might be governed by such a recessive gene remains to be determined.

1 Rothmund A. Ueber cataracte in verbindung mit einer eigenthuemlichen hautdegeneration. Graefes Arch Klin Exp Ophthalmol 1868;14:159-82.

2 Thomson MS. A hitherto undescribed familial disease. $\operatorname{Br} \mathcal{F}$ Dermatol 1923;35:455-61.

3 Thomson MS. Poikiloderma congenitale. Brf Dermatol 1936;48: 221-34.

4 Franceschetti A. Les dysplasies ectodermiques et les syndromes hereditaires apparentes. Dermatologica 1953;106:129-56.

5 Silver HK. Rothmund-Thomson syndrome: an oculocutaneous disorder. Am $\mathcal{F}$ Dis Child 1966;111:182-90.

6 McKusick VA. Mendelian inheritance in man. 7th ed. Baltimore: Johns Hopkins University Press, 1986.

7 Schinzel A, Biro Z, Schmidt W, Hayashi K. Trisomy 8 mosaicism syndrome. Helv Paediatr Acta 1974;29:531-40.

8 Hall JG, Pagon RA, Wilson KM. Rothmund-Thomson syndrome with severe dwarfism. Am $\mathcal{F}$ Dis Child 1980;134:165-9.

9 Uitto J, Bauer EA, Santa-Cruz DJ, Loewinger RJ, Eisen AZ. Focal dermal hypoplasia: abnormal growth characteristics of skin fibroblasts in culture. $\mathcal{F}$ Invest Dermatol 1980;75:170-5.

10 Taylor WB. Rothmund's syndrome-Thomson's syndrome. $A M A$ Arch Dermatol 1957;73:236-43.

11 Starr DG, McClure JP, Connor JM. Non-dermatological complications and genetic aspects of the Rothmund-Thomson syndrome. Clin Genet 1985;27:102-4. 